\title{
The gut microbiome in Western and Indigenous cultures
}

\author{
Santanu Das ${ }^{1}$, Tahila Andrighetti ${ }^{5}$, João Sabino ${ }^{2,6}$, Tamas Korcsmaros ${ }^{2,3}$, Mojibur \\ Rohman Khan ${ }^{1}$, Séverine Vermeire ${ }^{2,6}$, Padhmanand Sudhakar ${ }^{2,3,4}$ \\ ${ }^{1}$ Molecular Biology and Microbial Biotechnology Laboratory, Division of Life Sciences, Institute of \\ Advanced Study in Science and Technology (IASST), Guwahati \\ ${ }^{2} \mathrm{KU}$ Leuven Department of Chronic Diseases, Metabolism and Ageing, Translational Research Center for \\ Gastrointestinal Disorders (TARGID), Leuven, Belgium. \\ ${ }^{3}$ Earlham Institute, Norwich, United Kingdom. \\ ${ }^{4}$ Quadram Institute, Norwich, United Kingdom. \\ ${ }^{5}$ Laboratory of Structural Bioinformatics and Computational Biology (SBCB), Institute of Informatics, \\ Federal University of Rio Grande do Sul (UFRGS), Av. Bento Gonçalves 9500, 91501-970 - Porto Alegre, \\ RS - Brazil \\ ${ }^{6}$ Department of Gastroenterology and Hepatology, KU Leuven University Hospitals Leuven, Leuven, \\ Belgium \\ Corresponding author: \\ Padhmanand Sudhakar \\ IBD group \\ Translational Research of Gastroenterological Disorders (TARGID) \\ ON I Herestraat 49 - box 701 3000, KU Leuven \\ Leuven, Belgium
}

\begin{abstract}
The mammalian gut ecosystem plays critical roles in multiple functions related to health and homeostasis. In many cases, disturbances in the gut ecosystem are associated with a large number of metabolic and chronic diseases and disorders such as diabetes, cancer, and obesity. A diverse community of microorganisms ranging from viruses to bacteria comprise the gut microbiota, which is often considered as an organ in itself. Recent studies have profiled the influence of lifestyles and dietary behavior by comparing the gut microbiome of populations with different cultural underpinnings. In this review, we provide an overview of the studies which report the influence on the gut microbial composition of dietary and lifestyle patterns in different contexts such as western industrialized countries and indigenous cultures (corresponding to different lifestyle gradients such as hunter-gatherers and pastoralists) and how this association may influence health and disease.
\end{abstract}

Keywords: Gut microbiome; Western and indigenous/traditional cultures; gut health; disease; lifestyle; novel microbials 


\section{Introduction}

Human beings are social in nature and like to stay in company. The human body is a good example of this unison where our cells live in a symbiotic association with trillions of microbial entities. Collectively known as the microbiota and their gene pool as microbiome, these microorganisms are present at various sites in the human body including the gastrointestinal (GI) tract. Within the GI tract, the type and the count of microbes varies as we move down to the colon. In the stomach, which is highly acidic in nature, the microbial count is $10^{10}$ cells/gm (of gut content) and clades like Helicobacter dominate this niche. However, when moving down to the colon the count of bacteria increases to $10^{14}$ cells/gm (of gut content), with diverse flora dominating the niche (Jandhyala et al., 2015; Adak and Khan, 2019). This resident microbial population confers the host with an array of benefits which includes nutrient metabolism. The gut microbiome helps in the digestion of carbohydrates and lipids, and also aids in the synthesis, transformation, and absorption of nutrients such as essential vitamins and amino acids (Shreiner et al., 2015). The gut microbiota plays an important role in shaping the immune system, thanks to the interactions of commensal bacteria with different host cell-types including immune cells (Belkaid and Hand, 2014). Furthermore, the gut microbiota also plays a role in the barrier protection and in preventing colonization of the invading pathogens (Lazar et al., 2018; $\mathrm{Wu}$ and $\mathrm{Wu}, 2012$ ). However, the normal function of the gut microbiota is perturbed upon dysbiosis, a term used to describe the disruption of the composition and/or activity of the gut microbiota. Dysbiosis has been associated with intestinal disorders such as inflammatory bowel diseases (IBD) (Lloyd-Price et al., 2019; Schirmer et al., 2018). With awareness and increased health concerns, there is a paradigm shift (Green et al., 2019; Lewis, 2016; Pigneur and Ruemmele, 2019; Ananthakrishnan, 2020) in search of novel therapies targeting dysbiosis for which diet based interventions are being considered and investigated (Svolos et al., 2019; de Castro et al., 2020) .

The gut microbiome is dynamic in its composition and passes through several transitions. It has been reported that various factors like age, geography, ethnicity, birth delivery, breast feeding, diet, lifestyle, use of antibiotics_and medicines play an important role to shape the gut microbiome of an individual (Jandhyala et al., 2015; Zhernakova et al., 2016) (Falony et al., 2016) (Figure 1). However, many recent studies comparing the gut microbiomes of different communities have established the fact that it varies with changes in dietary practices and lifestyle (Singh et al., 2017; Sonnenburg et al., 2016; Wu et al., 2011). The migration of modern human beings from a nomadic lifestyle to industrialized lifestyle, along with associated changes in the diet have profoundly impacted the microbial population of the gut (Jha et al., 2018). Often the changes associated with this shift are found to be detrimental and are also associated with various metabolic syndromes and other diseases, such as inflammatory bowel disease and irritable bowel syndrome (Nicholson et al., 2012; Jha et al., 2018; Brooks et al., 2018). 


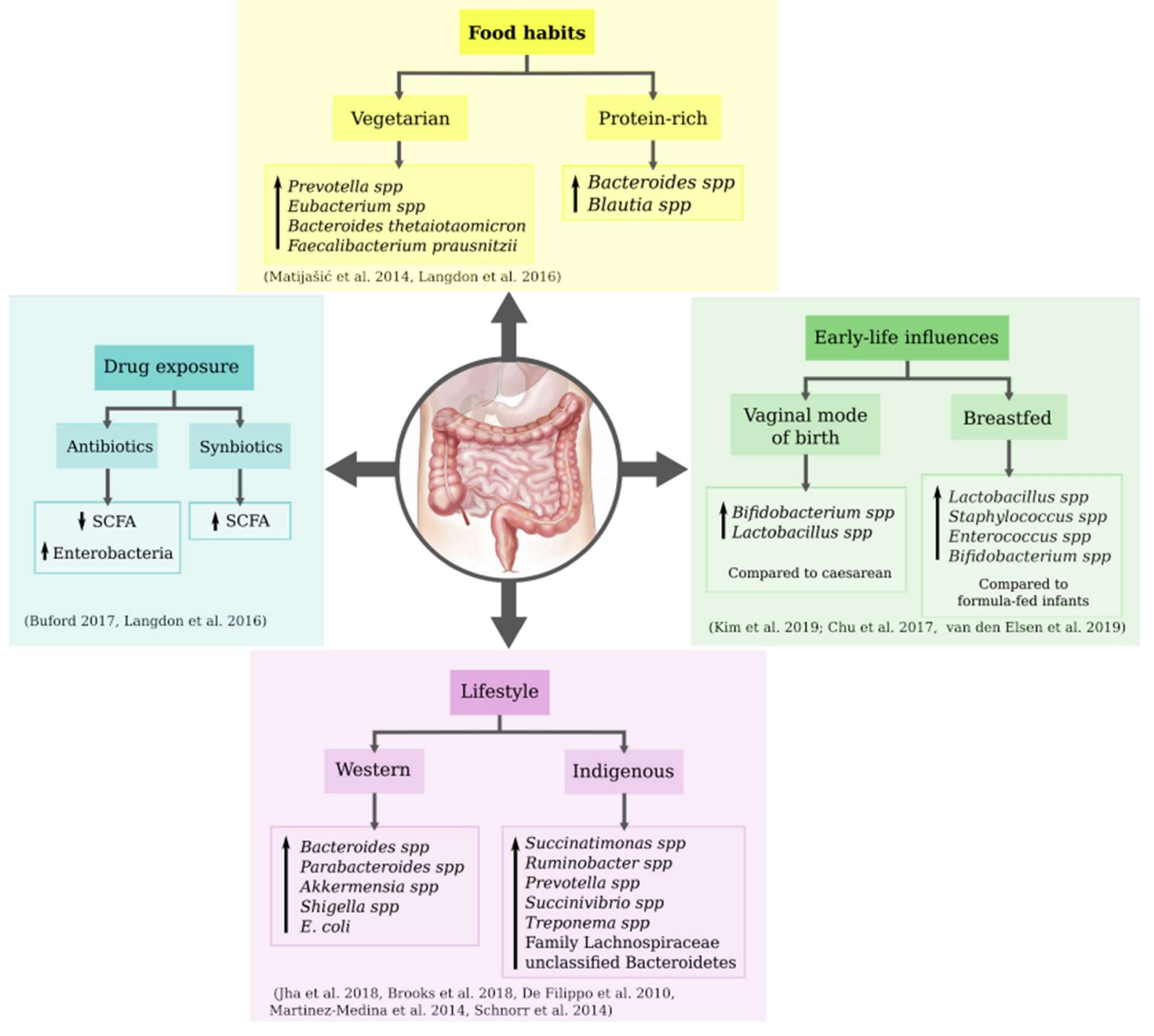

Figure 1. A graphical illustration of some of the extrinsic factors (exposome) affecting the alterations in the gut microbial composition.

The purpose of this review is to explore the differences in the gut microbial community between human populations exposed to and not exposed to the influences of westernization and industrialization. The dietary and nutritional factors responsible for this drastic change are also accounted for. Through this review, we have tried to highlight potential dietary practices which might be helpful in maintaining a healthy gut microbiome and subsequently a healthy gut.

\section{Factors affecting the gut microbiome}

The human gut microbiome is dynamic in nature and is synchronous with several vital functions and exposures (Kim and Jazwinski, 2018). The birth mode of an individual determines the early colonizers of the gut microbiome. Infants born through vaginal delivery harbor more 
Bifidobacterium and Lactobacillus as opposed to their counterparts born through cesarean section (Kim et al., 2019; Chu et al., 2017). Various studies have shown that the infant gut microbiome is seeded by breast milk in a dose dependent manner (Derrien et al., 2019). In a study encompassing 7 different populations, infants exclusively breastfed harbored a more stable gut microbiome and the predicted functional pathways were enriched for carbohydrate metabolism. On the contrary, some of the candidates of gut microbiota in case of non-breast fed infants resembles more closely to that of the adult microbiota. The enriched functional pathways of the microbiome relates to lower abundance of lipid metabolism, detoxification, and cofactor and vitamin metabolism (Ho et al., 2018). Bacteria belonging to genera such as Lactobacillus, Staphylococcus, Enterococcus, and Bifidobacterium are enriched by breastfeed (Berger et al., 2020b; Bashiardes et al., 2016). The human milk oligosaccharides (HMO) along with glycomacropeptide, a collection of complex sugar structures that are not digestible by the infants, serves as substrate for the bifidogenic and lactic acid bacteria to thrive on (Kim et al., 2019; van den Elsen et al., 2019; Salli et al., 2019; Berger et al., 2020a). Secretory IgA antibodies (originating from plasma cells of the maternal gut) and antimicrobial peptides present in breast milk have anti-pathogenic effects while the immune system is still in development and maturation (van den Elsen et al., 2019). In fact, the collection of milk microbes and HMOs exerts both probiotics and prebiotics effects on the gut of a breastfed infant paving a foundation for the development of a healthy microbiome (Wang et al., 2015; Berger et al., 2020a).

The gut microbiota stabilizes at around three years of age and at this stage, the microbiota transitions into a more stable and resilient form and composition (Derrien et al., 2019). It is thereafter exposed to various other influences such as diverse dietary ingredients, antibiotics and other medications(O'Toole and Jeffery, 2015; Yatsunenko et al., 2012; Zhong et al., 2019; De Filippo et al., 2010; Vatanen et al., 2018; Stewart et al., 2018; Willing et al., 2011; Oldenburg et al., 2018). The type of dietary ingredients in particular determines the resident microflora : for example, Prevotella and Eubacterium are enriched in a vegetarian diet whereas Bacteroidetes and Blautia are signatures of protein-rich and western diets (Brooks et al., 2018; Barone et al., 2019; Schnorr et al., 2014; Yatsunenko et al., 2012; Liu et al., 2016). Further, exposure to dietary supplements, antibiotics and other non-antibiotic drugs are associated with a transient change in the microbiota. For example, ciprofloxacin, a wide spectrum antibiotic, decreases the taxonomic richness, diversity, and evenness of the gut microbial community (Dethlefsen et al., 2008). Extensive use of pharmaceuticals may also be a contributing factor leading to a decrease in the microbiome diversity in modern Western societies (Maier et al., 2018) (Buford, 2017). Parallel with the ageing process, the diversity of the gut microbiome decreases, although an increase in pathobionts is observed, and expression of genes involved in SCFA production decreases (Rampelli et al., 2013). Another determinant of the microbiome is the lifestyle and geography of an individual and/or community (Gupta et al., 2017). There are considerable differences in the lifestyles of the western populations in comparison with others. Many African lifestyles can be considered as semi-nomadic, huntergatherers, and foragers, while American, Asian, and European populations can be considered to have industrialized lifestyles. Comparative studies on those cohorts have shown that the nomadic or hunter-gatherer microbiome is enriched with Succinatimonas, Ruminobacter, Prevotella, Succinivibrio, and members of Lachnospiraceae, whereas Bacteroides, Parabacteroides, and Akkermensia dominate the gut microbiome of western populations (Jha et al., 2018; Brooks et al., 2018). Therefore, diet along with lifestyle plays a pivotal role in shaping an individual's microbiome over time. 


\section{Influence of diets and dietary components on the gut microbiome}

Studies which investigate diet-gut microbiome relationships and the resulting functions have either tended to focus on entire dietary regimens or on particular components such as dietary fiber or dietary supplements. Due to the scope and scale of this review, it is impossible to cover the entirety of such studies. Prominent examples from each of the above-mentioned categories of studies are highlighted to provide a diverse overview.

Comparison between completely animal-based vs plant-based diets resulted in the enrichment of bile-tolerant microbial communities and reduction in microbes which rely on plant-derived carbohydrate substrates (David et al., 2014; De Angelis et al., 2020). Another study evaluating the effects of omnivorous and vegetarian diets on the fecal gut microbial composition using PCRdenaturing gradient gel electrophoresis (DGGE) fingerprinting of the V3 16S rRNA region demonstrated a high ratio of beneficial microbes such as Bacteroides thetaiotaomicron and Faecalibacterium prausnitzii in individuals consuming vegetarian diets (Matijašić et al., 2014). In contrast to the western diets, rural diets high in fiber content increase the fraction of bacterial species with xylan and cellulose metabolism encoding genes. In addition, bacteria such as Shigella and Escherichia coli - which have been frequently associated with GI disorders such as IBD - were also over-represented in the gut microbiome of individuals consuming Western diets (De Filippo et al., 2010; Martinez-Medina et al., 2014). Using humanized gnotobiotic mice and metagenomic profiling, drastic changes in microbial signatures, pathway activation and host gene expression upon transitioning from a low-fat plant polysaccharide-rich diet to a high-fat, high-sugar western diet were observed (Turnbaugh et al., 2009). Metagenomic study on human volunteers reveals that the composition and activities of the gut microbiota changes in response to the dietary preferences. It was observed that a plant-based diet constituting mostly of grains, legumes, fruits and vegetables enhances the growth of Roseburia, Eubacterium rectale, and Ruminococcus bromii, among others. On the other hand, animal-based diet constituting mostly of meats, eggs, cheese, dairy products promotes the proliferation of Alistipes, Bilophila and Bacteroides. Collective inferences from various studies investigating the effects of Mediterranean diets on the gut microbiome revealed patterns suggesting the positive effects of the diet which included reduction in inflammatory markers (Figure 2), enrichment of beneficial species including those occupying keystone functionalities and increased levels of short-chain fatty acids (De Filippis et al., 2016; GarciaMantrana et al., 2018). The effects of other types of dietary schemes such as modern Paleolithic diets and raw-food diets have also been studied (Barone et al., 2019; Carmody et al., 2019). Individuals consuming modern Paleolithic diets were characterized as having a highly diverse gut microbiome with many peculiar features such as an increased abundance of microorganisms tolerant to bile-acids in addition to a high proportion of lipophilic microbes (Barone et al., 2019). Consumption of cooked vs raw foods was also shown to impact the composition of the gut microbiome with many of the alterations related to the microbiome's ability to assimilate carbohydrates (Carmody et al., 2019). Based on the above discussed studies, it can be generalized that plant-based diets and diets rich in plant-based dietary fibers select for and enrich microbial communities which are largely beneficial. 


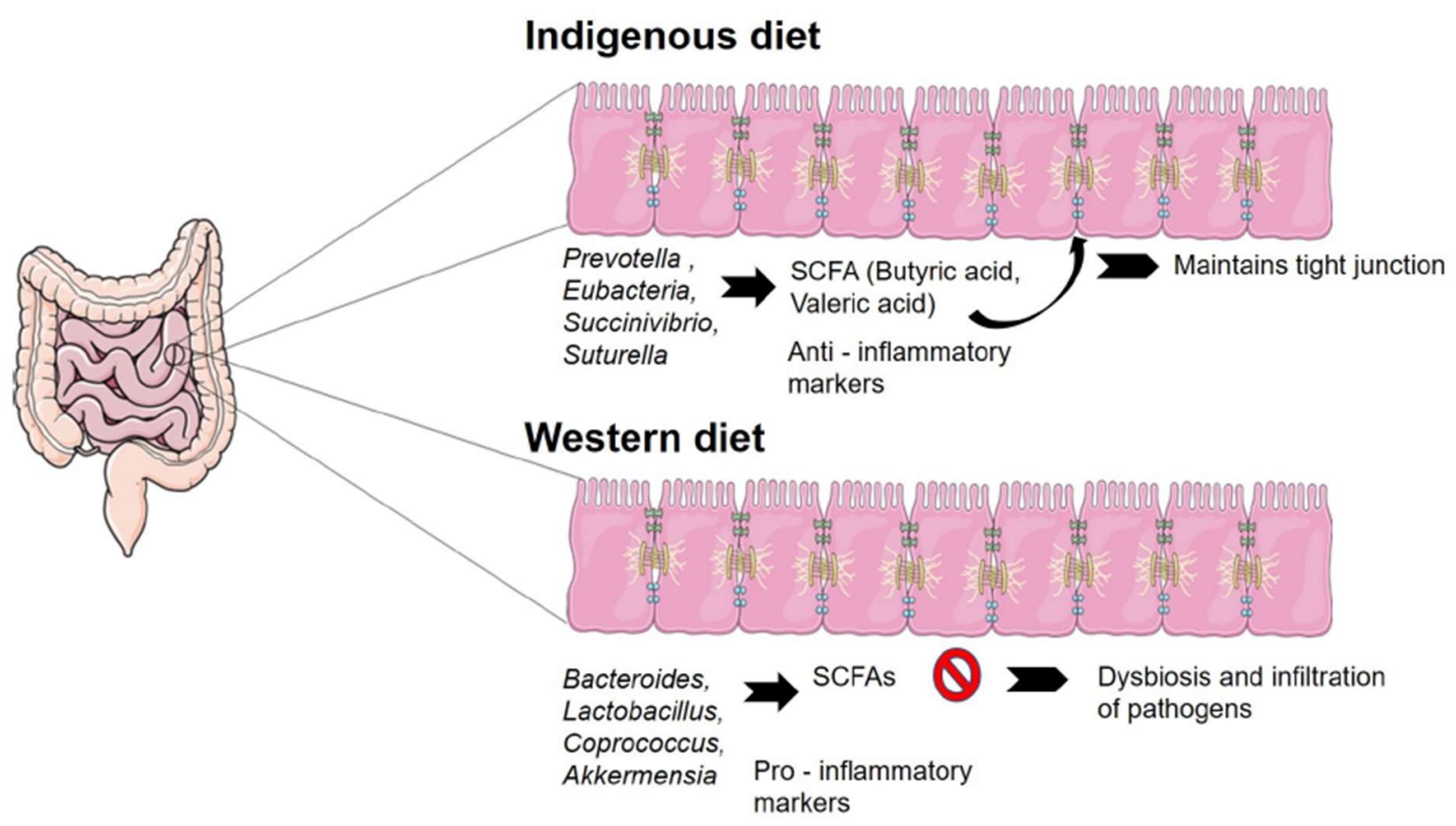

Figure 2. The influence of western and indigenous (includes non-Western diets such as Mediterranean diets) diets on inflammatory markers and barrier integrity.

\section{The gut microbiome in indigenous cultures}

Due to the differences in the dietary patterns between indigenous communities and Western societies and to understand/appreciate the true diversity of the gut microbiome, various studies have focused on the composition and content of the gut microbiome in indigenous communities and uncontacted tribes. Cultural underpinnings, socio-ecological interactions and lifestyles such as the manner in which subsistence (food procurement) is practiced, is known to influence the gut microbiome (Obregon-Tito et al., 2015; Girard et al., 2017; Schnorr et al., 2014; Stagaman et al., 2018; Jha et al., 2018) (Table 1). Comparisons between people leading hunter-gatherer lifestyles and urbanized populations not only reveal metabolic and taxonomic differences (Obregon-Tito et al., 2015; Clemente et al., 2015) but also link the richness and diversity of the microbial communities to dietary intakes (Obregon-Tito et al., 2015; Schnorr et al., 2014). The dietary patterns of the isolated Inuit populations and the Canadian urban communities were different at the species and strain levels despite converging diversity signatures at the community level (Girard et al., 2017). Particular genera of bacteria are also selected to become dominant in order to enhance the host digestive potential as demonstrated by the enrichment of Prevotella, Treponema, and unclassified Bacteroidetes in the Hadza hunter gatherers who rely on a variety of plant based foods with high fibrous content (Schnorr et al., 2014). Other studies have identified the detrimental effects of economic development on the intestinal microbiota of indigenous populations (Stagaman et al., 2018). Economic development as measured by the use of modern housing and decreasing components of traditional lifestyles of indigenous populations in Ecuador were correlated with loss of within-host diversity and reduction in beneficial bacterial taxa (Stagaman et al., 2018). 
Table 1. A comparison of the dietary factors and corresponding gut microbes of western and indigenous/ethnic communities. $\neq$ indicates the positive association of taxa with Ulcerative Colitis (UC) (Kostic et al., 2014) (Gevers et al., 2014) * indicates a negative association of taxa with Crohn's disease (CD) \# indicates a positive association of taxa with Crohn's disease (CD)(Gevers et al., 2014)

\begin{tabular}{|c|c|c|c|}
\hline Community & Common dietary items & Signature taxon/ Predominant taxon & References \\
\hline $\begin{array}{l}\text { Hadza Hunter- } \\
\text { gatherers of } \\
\text { Tanzania }\end{array}$ & $\begin{array}{l}\text { Meat, Honey, Baobab, Berries } \\
\text { and Tubers }\end{array}$ & $\begin{array}{l}\text { Prevotella, Eubacterium, Oscillibacter, } \\
\text { Butyricicoccus*, Sporobacter, } \\
\text { Succinivibrio and Treponema }\end{array}$ & $\begin{array}{l}\text { (Schnorr et } \\
\text { al., 2014; } \\
\text { Smits et al., } \\
\text { 2017) }\end{array}$ \\
\hline Italian & $\begin{array}{l}\text { Mediterranean diet: abundant } \\
\text { plant foods, fresh fruit, pasta, } \\
\text { bread and olive oil; low-to- } \\
\text { moderate amounts of dairy, } \\
\text { poultry, fish and red meat }\end{array}$ & $\begin{array}{l}\text { Bifidobacterium }^{\#}, \text { Blautia*, }^{*} \\
\text { Fusobacterium }^{\ddagger} \text { etc. }\end{array}$ & $\begin{array}{l}\text { (Schnorr et } \\
\text { al., 2014) }\end{array}$ \\
\hline $\begin{array}{l}\text { Guahibo } \\
\text { Amerindians }\end{array}$ & $\begin{array}{l}\text { Predominantly corn and } \\
\text { Cassava with meat, fish fruit } \\
\text { and vegetables }\end{array}$ & $\begin{array}{l}\text { Prevotella, Bacteroidales, Dialister, } \\
\text { Succinivibrio }\end{array}$ & $\begin{array}{l}\text { (Yatsunenko } \\
\text { et al., 2012) }\end{array}$ \\
\hline Malawi & $\begin{array}{l}\text { Predominantly corn and } \\
\text { Cassava with meat, fish fruit } \\
\text { and vegetables }\end{array}$ & Prevotella, Dialister, Succinivibrio & $\begin{array}{l}\text { (Yatsunenko } \\
\text { et al., 2012) }\end{array}$ \\
\hline$B a A k a$ & $\begin{array}{l}\text { Gozo, bitter manioc leaves, } \\
\text { koko leaves, peanut sauce, Blue } \\
\text { duiker meat }\end{array}$ & $\begin{array}{l}\text { Sutterella, Anaerovibrio, Clostridiaceae } \\
\text { and Cyanobacteria }\end{array}$ & $\begin{array}{l}\text { (Gomez et al., } \\
\text { 2016) }\end{array}$ \\
\hline Bantu & $\begin{array}{l}\text { Fibrous tubers, fibrous starchy } \\
\text { source like yam, etc. }\end{array}$ & $\begin{array}{l}\text { Ruminococcaceae, } \\
\text { Mogibacteriaceae, Faecalibacterium*, } \\
\text { Leuconostoc, Lactococcus, } \\
\text { Christenellaceae, and Dialister }\end{array}$ & $\begin{array}{l}\text { (Gomez et al., } \\
\text { 2016) }\end{array}$ \\
\hline Raji & $\begin{array}{l}\text { Natural tubers, green leafy } \\
\text { vegetables, fruits from jungle, } \\
\text { wild honey, fish and meat from } \\
\text { game }\end{array}$ & $\begin{array}{l}\text { Prevotella, Alloprevotella, and } \\
\text { Anaerophaga }\end{array}$ & $\begin{array}{l}\text { (Jha et al., } \\
\text { 2018) }\end{array}$ \\
\hline Raute & $\begin{array}{l}\text { Natural tubers, green leafy } \\
\text { vegetables, fruits from jungle, } \\
\text { wild honey, fish and meat from } \\
\text { game }\end{array}$ & $\begin{array}{l}\text { Prevotella, Alloprevotella, and } \\
\text { Anaerophaga }\end{array}$ & $\begin{array}{l}\text { (Jha et al., } \\
\text { 2018) }\end{array}$ \\
\hline
\end{tabular}




\begin{tabular}{|c|c|c|c|}
\hline Chepang & $\begin{array}{l}\text { Natural tubers, green leafy } \\
\text { vegetables, fruits from jungle, } \\
\text { wild honey, fish and meat from } \\
\text { game including Sinsu }\end{array}$ & $\begin{array}{l}\text { Ruminobacter, Campylobacter, and } \\
\text { Treponema }\end{array}$ & $\begin{array}{l}\text { (Jha et al., } \\
\text { 2018) }\end{array}$ \\
\hline Mongolian & $\begin{array}{l}\text { Cheese, fermented liquor and } \\
\text { red meat with carbohydrate } \\
\text { sources }\end{array}$ & $\begin{array}{l}\text { Actinomyces, Rothia, Catenibacterium, } \\
\text { Phascolarctobacterium, Sutterella and } \\
\text { Lactobacillus }\end{array}$ & $\begin{array}{l}\text { (Liu et al., } \\
\text { 2016) }\end{array}$ \\
\hline USA & $\begin{array}{l}\text { Processed, refined grain and } \\
\text { sugars as a source of } \\
\text { carbohydrates, processed meat, } \\
\text { high fat diet }\end{array}$ & $\begin{array}{l}\text { Bacteroides", Akkermensia, Odoribacter, } \\
\text { Verrucomicrobia, Prevotella }\end{array}$ & $\begin{array}{l}\text { (Brooks et } \\
\text { al., 2018; } \\
\text { Barone et al., } \\
2019)\end{array}$ \\
\hline $\begin{array}{l}\text { Flemish Gut } \\
\text { flora project } \\
\text { (Belgium) }\end{array}$ & $\begin{array}{l}\text { Processed, refined grain and } \\
\text { sugars as a source of } \\
\text { carbohydrates, processed meat, } \\
\text { high fat diet }\end{array}$ & $\begin{array}{l}\text { Feacalibacterium }{ }^{*} \text {, Coprococcus } \\
\text { Flavonifracctor, Dialister, } \\
\text { Butyricicoccus, Lactobacillus, Prevotella, } \\
\text { Bacteroidetes }\end{array}$ & $\begin{array}{l}\text { (Valles- } \\
\text { Colomer et } \\
\text { al., 2019; } \\
\text { Falony et al., } \\
\text { 2016) }\end{array}$ \\
\hline French & $\begin{array}{l}\text { Processed food materials and } \\
\text { dairy products }\end{array}$ & $\begin{array}{l}\text { Bifidobacterium, Prevotella, } \\
\text { Lactobacillus, Bacteroides, } \\
\text { Methanobrevibacter }\end{array}$ & $\begin{array}{l}\text { (Yasir et al., } \\
2015)\end{array}$ \\
\hline Dutch & $\begin{array}{l}63 \text { dietary factors including } \\
\text { sources of carbohydrates, } \\
\text { proteins, bread, soft-drinks, low } \\
\text { fat buttermilk }\end{array}$ & $\begin{array}{l}\text { Firmicutes, Actinobacteria and } \\
\text { Bacteroidetes, Leuconostoc } \\
\text { mesenteroides, Lactococcus lactis, } \\
\text { Faecalibacterium } \\
\text { prausnitzii*, Streptococcus and } \\
\text { Roseburia }\end{array}$ & $\begin{array}{l}\text { (Zhernakova } \\
\text { et al., 2016) }\end{array}$ \\
\hline
\end{tabular}

A multi-cohort study encompassing various populations inhabiting high-altitude environments in Nepal and Bolivia also identified common community level signatures which could support the metabolic and nutritional requirements of living in high altitudes (Quagliariello et al., 2019). A similar study involving four different Himalayan tribal communities reveal that distinct lifestyles characterized by varying degrees of agricultural practices are associated with differences in the gut microbial communities (Jha et al., 2018). Agricultural practices as well as other factors such as the source of drinking water and use of solid cooking fuel were also found to influence the shift of gut microbial signatures away from that of the foraging community (Jha et al., 2018). A landmark study by Dehingia et al (Dehingia et al., 2015) analyzing the gut bacterial profiles of fifteen different tribes in India, not only identified the influence of diet but also several core bacterial genera associated with indigenous communities. Despite the general agreement of increased diversity and richness of the gut microbiome in indigenous populations, even uncontacted tribal communities were shown to harbor antibiotic resistance genes in their gut microbiome, despite their lack of exposure to antibiotics (Clemente et al., 2015). 


\section{Distinguishing factors of western and traditional diets}

Dietary practice is the process through which an individual acquires nutrition and energy for maintaining the vital processes of the human body. Diet varies according to culture, social identity, religion, agricultural practices, and availability of food materials (Green et al., 2016). In the industrialized nations, due to lack of time and food production space, individuals depend on processed foods and ready to consume meals (Drake et al., 2018). Such a diet is characterized by increased in the intake of processed foods, artificial sweeteners, red meat and processed meats, high fat dairy products, refined grains and decreased in the consumption of whole grain, vegetables, fresh fruits, legumes, and fiber rich foods(Cordain et al., 2005). On the other hand, traditional diets such as the Mediterranean diet or diet of hunter-gatherers is characterized by a high intake of fresh fruits and vegetables, legumes, whole grains, pulses, and decreased consumption of added sugars and highly processed food materials (Romagnolo and Selmin, 2017). Inclusion of diverse plant materials in the diet results in the increase of alpha-diversity of gut microbes as it provides an array of substrates for various taxa to proliferate (Gomez et al., 2016). In the American Gut project, it was observed that SCFA producers like Faecalibacterium prausnitzii were abundant in individuals consuming 30 varieties of plant materials per week as compared to individuals consuming only 10 different varieties of plant species per week (McDonald et al., 2018). Faecalibacterium prausnitzii is a known butyrate producer and a positive indicator of good gut health (Ferreira-Halder et al., 2017). It's depletion in the gut has been described in intestinal diseases such as ulcerative colitis and colorectal cancer (Machiels et al., 2014) (Lopez-Siles et al., 2016). Since the Mediterranean diet and many other traditional diets are enriched in plant ingredients, the individuals are likely to harbor diverse gut microbes, as seen in the case of Hadza-hunters (Schnorr et al., 2014; Smits et al., 2017). Another cross-sectional study encompassing the traditional Mediterranean and western diets have demonstrated a positive correlation among vegetable-based diets and increased levels of faecal SCFA, Prevotella, and some fiber-degrading Firmicutes (De Filippis et al., 2016). Non-western diets are rich in fruits, vegetables, cereals which are rich a source of fiber and polyphenols. While fibers act as substrates for the colonic commensals, both plantain fibers and polyphenols exert dual effect on the gut microbiome. Fibers acts as substrates for the colonic commensals and also inhibits translocation of Escherichia coli. ((Roberts et al., 2010))Polyphenols specifically inhibit the growth of pathogens such as Helicobacter pylori and Clostridium difficile, while promoting the proliferation of bacteria from the genera Ruminococcus, Clostridium coccoides, Bacteroides, and Bifidobacterium spp., which metabolize polyphenols into bioavailable substrates for the host (Cardona et al., 2013; Heiman and Greenway, 2016).

Dishes and diets from particular dietary cultures have also been studied in the context of their influence on the gut microbiome. Indian food preparation includes a variety of spices such as coriander, cumin, fennel seeds, ginger, and garlic. The role of these spices is not just limited to the impartation of flavours but also extends to nutritional aspects. For example, it is reported that ginger contains exosome-like-nanoparticles (ELN), which harbors RNA(Chen et al., 2019b). Fecal microbiome analysis of mice fed with purified ginger derived ELN (GELN) shows substantial increase in the population of Lactobacillaceae. In vitro studies with GELN also demonstrated that GELN promotes the growth of Lactobacillus rhamnosus, which in turn aids in the release of IL-22 - a cytokine known to promote barrier repair and to restore homeostasis in certain contexts (Zhang et al., 2019). It has also been observed that the ingestion of curcumin changes the ratio between beneficial and pathogenic bacteria (Di Meo et al., 2019). Consumption of garlic is also known to impart beneficial effects on the gut microbiome by preventing dysbiosis (Chen et al., 2019a). 
However more studies with larger sample sizes are required to draw a conclusion on the effect of various components in the Indian diet on the gut microbiome. As discussed earlier, long term consumption of western diet depletes the gut microbial diversity and can potentially remove the beneficial dwellers on a permanent basis.

\section{How the dietary differences are modulating the maintenance of healthy/unhealthy gut ecosystem}

During the process of digestion, the enterocytes absorb the nutrients released from food materials (Karasov and Douglas, 2013). As the western diet is composed majorly of refined food materials, it provides the microbial and host cells with more easily digestible substrates. This in turn affects the absorption kinetics and hampers the metabolic functions of the microbiota (Spreadbury, 2012; Zinöcker and Lindseth, 2018). In contrast to the indigenous cultures, people living in industrial communities do not produce their own food and also rely on processed food. In order to meet the increasing demand, several artificial pesticides and fertilizers are applied for enhanced crop production.(Yuan et al., 2019) These chemical compounds are carried over to the plate and enter the intestinal tract upon ingestion. Studies with animal models suggest that pesticides and fertilizers decrease the abundances of important commensals like Prevotella, Bifidobacteria, Lactobacillus, thereby responsible for altering the gut microbiota composition and their metabolites, including TMA, bile acids, and SCFAs (Joly Condette et al., 2015; Reygner et al., 2016; Réquilé et al., 2018; Jin et al., 2019, 2018). Long term exposure to such compounds has been associated with diabetes and insulin resistance (Yuan et al., 2019; 2019; Kim et al., 2014). In animal models, pesticides have been associated with detrimental microbiota changes (Yuan et al. 2019).

Another important factor in diet is the varying availability of various cellular nutrients during digestion in the gut according to the nature of the food. As animal cells lack a cell wall, the plasma membrane is easily hydrolysed by the digestive enzymes thereby releasing the cellular contents into the gut lumen. These nutritional factors are taken up by the enterocytes with minimum or no aid from the microbiome (Karasov and Douglas, 2013). Similarly, during the process of refining of grains and pulses, a substantial amount of cell wall is damaged liberating the fibrous materials (Vanegas et al., 2017). These foods are also processed easily by the digestive machinery of the human body. On the contrary, whole grains, legumes and plant based products which make up the bulk of plant based diets are not readily available to the enterocytes (Zinöcker and Lindseth, 2018). During mastication of such products, only a trace amount of these nutrients is released for uptake in the small intestine (Grundy et al., 2016). However, absorption of nutrients is dispersed along the length of the small intestine and some food materials reaches the colon undigested, based on the complexity of its matrix. The colonic commensal bacteria hydrolyses the fiber rich cell wall, releasing nutritional factors that enter various metabolic cycles after being metabolised (Spreadbury, 2012).

Moreover, the almost ubiquitous chemical and preservatives used in the processing of food also negatively impacts the microbiome and other functions of the digestive tract. It has been reported that the emulsifiers and artificial sweeteners used in foods increases virulence factors and thereby the pro-inflammatory potential of the microbiome (Roberts et al., 2010; Suez et al., 2014; Chassaing et al., 2015). Emulsifiers and artificial sweeteners are widely used in processed foods and thus are present in most of the diets consumed by industrialized populations (Partridge et al., 2019). Increased uptake of emulsifiers could increase the susceptibility to Crohn's disease by increasing 
the bacterial translocation (Roberts et al., 2010). In an in-vitro study, it was established that E. coli had an increased translocation across M-cells under the influence of Polysorbate-80. This effect was however reverted back by treating the M-cells with soluble plant fiber (Roberts et al., 2010). Another study reports that the low concentration of carboxymethylcellulose (CMC) and polysorbate-80 (two of the most commonly used emulsifiers) induces low grade inflammation in wild type mice(Viennois et al., 2017). Non-absorbent artificial sweeteners (NAS) can also lead to various metabolic syndromes by altering the compositional and functional aspects of the gut microbiome (Suez et al., 2014). A study on the artificial sweetener consumption in both humans and mice reported the decrease in the counts of Clostridales and over-representation of Bacteroides (Suez et al., 2014). Both the bacteria were previously linked to type-2-diabetes (Chassaing et al., 2017, 2015) and were found to be involved in NAS induced phenotypes suggesting the effective association of NASs and the gut microbiome (Chassaing et al., 2017).

\section{Conclusion}

Multiple lines of evidence suggest that the lifestyle and dietary habits of indigenous populations have beneficial impacts on their gut microbiome. Based on several pre-clinical, observational, invivo and in-vivo studies, the evidence points to diet-specific signatures of the gut microbiome in various populations exposed to different environmental stimuli. These stimuli include levels of westernization and economic integration, degree of industrialization, and adoption of agricultural practices. However, certain traditional dietary habits are prone to demerits of their own; a study on the traditional diets of Eastern European nations have demonstrated an increase in cardiovascular diseases and cancer mortality rates (Stefler et al., 2020)

Nevertheless, given the burden of gut-related diseases on public health spending and quality of life indices, it is imperative that we don't lose sight of the possible beneficial impacts of diets and lifestyles on the gut microbiome in different cultural contexts. Furthermore, the gut microbiome of diverse human populations could be a source of novel microbial species with beneficial metabolic properties. At a mechanistic level though, knowledge is lacking in terms of how dietary and lifestyle factors select for various microbial species and how these species in turn contribute either to homeostasis or disease. A combination of experimental and computational techniques investigating microbe-host interactions at various levels such as protein-protein interactions and metabolic cofeeding is expected to provide us with a detailed understanding of the mechanisms involved.

\section{Author contributions}

SD and PS performed the literature search. SD, PS and TA wrote the manuscript and compiled the figures and tables. JS, TK, MRK and SV provided supervision and contributed to critical discussion in the manuscript. All the authors read and approved the final manuscript.

\section{Funding}

SD is thankful to Department of Biotechnology (DBT), India sponsored Unit of Excellence Project (BT/550/NE/U-Excel/2014) and Department of Science and Technology (DST), India for providing financial support to carry out research work. P.S. was supported by funding from the European Research Council (ERC) under the European Union's Horizon 2020 research and innovation programme (grant agreement no. 694679). TA was supported by CAPES - the Brazilian Federal Agency for Support and Evaluation of Graduate Education within the Ministry 
of Education of Brazil - and by a PhD scholarship supported by $\mathrm{CNPq}$ - Brazilian National Council for Scientific and Technological Development. JS is supported by a senior clinical investigator fellowship from the Research Foundation Flanders (FWO), Belgium. SV is a senior clinical investigator of the Research Foundation Flanders (FWO), Belgium. TK was supported by a fellowship in computational biology at the Earlham Institute (Norwich, UK) in partnership with the Quadram Institute (Norwich, UK) and was strategically supported by the BBSRC (BB/J004529/1, BB/P016774/1 and BB/CSP17270/1).

\section{Bibliography}

Matijašić, B. B., Obermajer, T., Lipoglavšek, L., Grabnar, I., Avguštin, G., and Rogelj, I. (2014). Association of dietary type with fecal microbiota in vegetarians and omnivores in Slovenia. Eur J Nutr 53, 1051-1064. doi:10.1007/s00394-013-0607-6.

McDonald, D., Hyde, E., Debelius, J. W., Morton, J. T., Gonzalez, A., Ackermann, G., Aksenov, A. A., Behsaz, B., Brennan, C., Chen, Y., et al. (2018). American gut: an open platform for citizen science microbiome research. mSystems 3. doi:10.1128/mSystems.00031-18.

Di Meo, F., Margarucci, S., Galderisi, U., Crispi, S., and Peluso, G. (2019). Curcumin, gut microbiota, and neuroprotection. Nutrients 11. doi:10.3390/nu11102426.

Nicholson, J. K., Holmes, E., Kinross, J., Burcelin, R., Gibson, G., Jia, W., and Pettersson, S. (2012). Host-gut microbiota metabolic interactions. Science 336, 1262-1267. doi:10.1126/science. 1223813 .

O'Toole, P. W., and Jeffery, I. B. (2015). Gut microbiota and aging. Science 350, 1214-1215. doi:10.1126/science.aac8469.

Obregon-Tito, A. J., Tito, R. Y., Metcalf, J., Sankaranarayanan, K., Clemente, J. C., Ursell, L. K., Zech Xu, Z., Van Treuren, W., Knight, R., Gaffney, P. M., et al. (2015). Subsistence strategies in traditional societies distinguish gut microbiomes. Nat. Commun. 6, 6505. doi:10.1038/ncomms7505.

Oldenburg, C. E., Sié, A., Coulibaly, B., Ouermi, L., Dah, C., Tapsoba, C., Bärnighausen, T., Ray, K. J., Zhong, L., Cummings, S., et al. (2018). Effect of commonly used pediatric antibiotics on gut microbial diversity in preschool children in burkina faso: A randomized clinical trial. Open Forum Infect. Dis. 5, ofy289. doi:10.1093/ofid/ofy289.

Partridge, D., Lloyd, K. A., Rhodes, J. M., Walker, A. W., Johnstone, A. M., and Campbell, B. J. (2019). Food additives: Assessing the impact of exposure to permitted emulsifiers on bowel and metabolic health - introducing the FADiets study. Nutr. Bull. 44, 329-349. doi:10.1111/nbu.12408.

Pigneur, B., and Ruemmele, F. M. (2019). Nutritional interventions for the treatment of IBD: current evidence and controversies. Therap. Adv. Gastroenterol. 12, 1756284819890534. doi:10.1177/1756284819890534.

Quagliariello, A., Di Paola, M., De Fanti, S., Gnecchi-Ruscone, G. A., Martinez-Priego, L., PérezVillaroya, D., Sherpa, M. G., Sherpa, P. T., Marinelli, G., Natali, L., et al. (2019). Gut microbiota composition in Himalayan and Andean populations and its relationship with diet, lifestyle and adaptation to the high-altitude environment. J. Anthropol. Sci. 96, 189208. doi:10.4436/JASS.97007.

Rampelli, S., Candela, M., Turroni, S., Biagi, E., Collino, S., Franceschi, C., O’Toole, P. W., and Brigidi, P. (2013). Functional metagenomic profiling of intestinal microbiome in extreme ageing. Aging (Albany, NY) 5, 902-912. doi:10.18632/aging.100623. 
Réquilé, M., Gonzàlez Alvarez, D. O., Delanaud, S., Rhazi, L., Bach, V., Depeint, F., and KhorsiCauet, H. (2018). Use of a combination of in vitro models to investigate the impact of chlorpyrifos and inulin on the intestinal microbiota and the permeability of the intestinal mucosa. Environ. Sci. Pollut. Res. Int. 25, 22529-22540. doi:10.1007/s11356-018-2332-4.

Reygner, J., Lichtenberger, L., Elmhiri, G., Dou, S., Bahi-Jaber, N., Rhazi, L., Depeint, F., Bach, V., Khorsi-Cauet, H., and Abdennebi-Najar, L. (2016). Inulin Supplementation Lowered the Metabolic Defects of Prolonged Exposure to Chlorpyrifos from Gestation to Young Adult Stage in Offspring Rats. PLoS One 11, e0164614. doi:10.1371/journal.pone.0164614.

Roberts, C. L., Keita, A. V., Duncan, S. H., O’Kennedy, N., Söderholm, J. D., Rhodes, J. M., and Campbell, B. J. (2010). Translocation of Crohn's disease Escherichia coli across M-cells: contrasting effects of soluble plant fibres and emulsifiers. Gut 59, 1331-1339. doi:10.1136/gut.2009.195370.

Romagnolo, D. F., and Selmin, O. I. (2017). Mediterranean diet and prevention of chronic diseases. Nutr. Today 52, 208-222. doi:10.1097/NT.0000000000000228.

Salli, K., Anglenius, H., Hirvonen, J., Hibberd, A. A., Ahonen, I., Saarinen, M. T., Tiihonen, K., Maukonen, J., and Ouwehand, A. C. (2019). The effect of 2'-fucosyllactose on simulated infant gut microbiome and metabolites; a pilot study in comparison to GOS and lactose. Sci. Rep. 9, 13232. doi:10.1038/s41598-019-49497-z.

Sarmiento, M. R. A., de Paula, T. O., Borges, F. M., Ferreira-Machado, A. B., Resende, J. A., Moreira, A. P. B., Dutra Luquetti, S. C. P., Cesar, D. E., da Silva, V. L., and Diniz, C. G. (2019). Obesity, Xenobiotic Intake and Antimicrobial-Resistance Genes in the Human Gastrointestinal Tract: A Comparative Study of Eutrophic, Overweight and Obese Individuals. Genes (Basel) 10. doi:10.3390/genes10050349.

Schirmer, M., Franzosa, E. A., Lloyd-Price, J., McIver, L. J., Schwager, R., Poon, T. W., Ananthakrishnan, A. N., Andrews, E., Barron, G., Lake, K., et al. (2018). Dynamics of metatranscription in the inflammatory bowel disease gut microbiome. Nat. Microbiol. 3, 337-346. doi:10.1038/s41564-017-0089-z.

Schnorr, S. L., Candela, M., Rampelli, S., Centanni, M., Consolandi, C., Basaglia, G., Turroni, S., Biagi, E., Peano, C., Severgnini, M., et al. (2014). Gut microbiome of the Hadza huntergatherers. Nat. Commun. 5, 3654. doi:10.1038/ncomms4654.

Shondelmyer, K., Knight, R., Sanivarapu, A., Ogino, S., and Vanamala, J. K. P. (2018). Ancient thali diet: gut microbiota, immunity, and health. Yale J Biol Med 91, 177-184.

Shreiner, A. B., Kao, J. Y., and Young, V. B. (2015). The gut microbiome in health and in disease. Curr. Opin. Gastroenterol. 31, 69-75. doi:10.1097/MOG.0000000000000139.

Singh, R. K., Chang, H.-W., Yan, D., Lee, K. M., Ucmak, D., Wong, K., Abrouk, M., Farahnik, B., Nakamura, M., Zhu, T. H., et al. (2017). Influence of diet on the gut microbiome and implications for human health. J. Transl. Med. 15, 73. doi:10.1186/s12967-017-1175-y.

Smits, S. A., Leach, J., Sonnenburg, E. D., Gonzalez, C. G., Lichtman, J. S., Reid, G., Knight, R., Manjurano, A., Changalucha, J., Elias, J. E., et al. (2017). Seasonal cycling in the gut microbiome of the Hadza hunter-gatherers of Tanzania. Science 357, 802-806. doi:10.1126/science.aan4834.

Sonnenburg, E. D., Smits, S. A., Tikhonov, M., Higginbottom, S. K., Wingreen, N. S., and Sonnenburg, J. L. (2016). Diet-induced extinctions in the gut microbiota compound over generations. Nature 529, 212-215. doi:10.1038/nature16504. 
Spreadbury, I. (2012). Comparison with ancestral diets suggests dense acellular carbohydrates promote an inflammatory microbiota, and may be the primary dietary cause of leptin resistance and obesity. Diabetes. Metab. Syndr. Obes. 5, 175-189. doi:10.2147/DMSO.S33473.

Stagaman, K., Cepon-Robins, T. J., Liebert, M. A., Gildner, T. E., Urlacher, S. S., Madimenos, F. C., Guillemin, K., Snodgrass, J. J., Sugiyama, L. S., and Bohannan, B. J. M. (2018). Market Integration Predicts Human Gut Microbiome Attributes across a Gradient of Economic Development. mSystems 3. doi:10.1128/mSystems.00122-17.

Stefler, D., Brett, D., Sarkadi-Nagy, E., Kopczynska, E., Detchev, S., Bati, A., Scrob, M., Koenker, D., Aleksov, B., Douarin, E., et al. (2020). Traditional Eastern European diet and mortality: prospective evidence from the HAPIEE study. Eur J Nutr. doi:10.1007/s00394-020-023199.

Stewart, C. J., Ajami, N. J., O’Brien, J. L., Hutchinson, D. S., Smith, D. P., Wong, M. C., Ross, M. C., Lloyd, R. E., Doddapaneni, H., Metcalf, G. A., et al. (2018). Temporal development of the gut microbiome in early childhood from the TEDDY study. Nature 562, 583-588. doi:10.1038/s41586-018-0617-x.

Suez, J., Korem, T., Zeevi, D., Zilberman-Schapira, G., Thaiss, C. A., Maza, O., Israeli, D., Zmora, N., Gilad, S., Weinberger, A., et al. (2014). Artificial sweeteners induce glucose intolerance by altering the gut microbiota. Nature 514, 181-186. doi:10.1038/nature13793.

Svolos, V., Hansen, R., Nichols, B., Quince, C., Ijaz, U. Z., Papadopoulou, R. T., Edwards, C. A., Watson, D., Alghamdi, A., Brejnrod, A., et al. (2019). Treatment of Active Crohn's Disease With an Ordinary Food-based Diet That Replicates Exclusive Enteral Nutrition. Gastroenterology 156, 1354-1367.e6. doi:10.1053/j.gastro.2018.12.002.

Turnbaugh, P. J., Ridaura, V. K., Faith, J. J., Rey, F. E., Knight, R., and Gordon, J. I. (2009). The effect of diet on the human gut microbiome: a metagenomic analysis in humanized gnotobiotic mice. Sci. Transl. Med. 1, 6ra14. doi:10.1126/scitranslmed.3000322.

Valles-Colomer, M., Falony, G., Darzi, Y., Tigchelaar, E. F., Wang, J., Tito, R. Y., Schiweck, C., Kurilshikov, A., Joossens, M., Wijmenga, C., et al. (2019). The neuroactive potential of the human gut microbiota in quality of life and depression. Nat. Microbiol. 4, 623-632. doi:10.1038/s41564-018-0337-x.

van den Elsen, L. W. J., Garssen, J., Burcelin, R., and Verhasselt, V. (2019). Shaping the gut microbiota by breastfeeding: the gateway to allergy prevention? Front. Pediatr. 7, 47. doi:10.3389/fped.2019.00047.

Vanegas, S. M., Meydani, M., Barnett, J. B., Goldin, B., Kane, A., Rasmussen, H., Brown, C., Vangay, P., Knights, D., Jonnalagadda, S., et al. (2017). Substituting whole grains for refined grains in a 6-wk randomized trial has a modest effect on gut microbiota and immune and inflammatory markers of healthy adults. Am. J. Clin. Nutr. 105, 635-650. doi:10.3945/ajen.116.146928.

Vatanen, T., Franzosa, E. A., Schwager, R., Tripathi, S., Arthur, T. D., Vehik, K., Lernmark, Å., Hagopian, W. A., Rewers, M. J., She, J.-X., et al. (2018). The human gut microbiome in early-onset type 1 diabetes from the TEDDY study. Nature 562, 589-594. doi:10.1038/s41586-018-0620-2.

Viennois, E., Merlin, D., Gewirtz, A. T., and Chassaing, B. (2017). Dietary Emulsifier-Induced Low-Grade Inflammation Promotes Colon Carcinogenesis. Cancer Res. 77, 27-40. doi:10.1158/0008-5472.CAN-16-1359. 
Wang, M., Li, M., Wu, S., Lebrilla, C. B., Chapkin, R. S., Ivanov, I., and Donovan, S. M. (2015). Fecal microbiota composition of breast-fed infants is correlated with human milk oligosaccharides consumed. J. Pediatr. Gastroenterol. Nutr. 60, 825-833. doi:10.1097/MPG.0000000000000752.

Willing, B. P., Russell, S. L., and Finlay, B. B. (2011). Shifting the balance: antibiotic effects on host-microbiota mutualism. Nat. Rev. Microbiol. 9, 233-243. doi:10.1038/nrmicro2536.

Wu, G. D., Chen, J., Hoffmann, C., Bittinger, K., Chen, Y.-Y., Keilbaugh, S. A., Bewtra, M., Knights, D., Walters, W. A., Knight, R., et al. (2011). Linking long-term dietary patterns with gut microbial enterotypes. Science 334, 105-108. doi:10.1126/science.1208344.

$\mathrm{Wu}, \mathrm{H} .-\mathrm{J}$. , and $\mathrm{Wu}, \mathrm{E}$. (2012). The role of gut microbiota in immune homeostasis and autoimmunity. Gut Microbes 3, 4-14. doi:10.4161/gmic.19320.

Yasir, M., Angelakis, E., Bibi, F., Azhar, E. I., Bachar, D., Lagier, J. C., Gaborit, B., Hassan, A. M., Jiman-Fatani, A. A., Alshali, K. Z., et al. (2015). Comparison of the gut microbiota of people in France and Saudi Arabia. Nutr. Diabetes 5, e153. doi:10.1038/nutd.2015.3.

Yatsunenko, T., Rey, F. E., Manary, M. J., Trehan, I., Dominguez-Bello, M. G., Contreras, M., Magris, M., Hidalgo, G., Baldassano, R. N., Anokhin, A. P., et al. (2012). Human gut microbiome viewed across age and geography. Nature 486, 222-227. doi:10.1038/nature11053.

Yuan, X., Pan, Z., Jin, C., Ni, Y., Fu, Z., and Jin, Y. (2019). Gut microbiota: An underestimated and unintended recipient for pesticide-induced toxicity. Chemosphere 227, 425-434. doi:10.1016/j.chemosphere.2019.04.088.

Zhang, X., Liu, S., Wang, Y., Hu, H., Li, L., Wu, Y., Cao, D., Cai, Y., Zhang, J., and Zhang, X. (2019). Interleukin-22 regulates the homeostasis of the intestinal epithelium during inflammation. Int. J. Mol. Med. 43, 1657-1668. doi:10.3892/ijmm.2019.4092.

Zhernakova, A., Kurilshikov, A., Bonder, M. J., Tigchelaar, E. F., Schirmer, M., Vatanen, T., Mujagic, Z., Vila, A. V., Falony, G., Vieira-Silva, S., et al. (2016). Population-based metagenomics analysis reveals markers for gut microbiome composition and diversity. Science 352, 565-569. doi:10.1126/science.aad3369.

Zhong, H., Penders, J., Shi, Z., Ren, H., Cai, K., Fang, C., Ding, Q., Thijs, C., Blaak, E. E., Stehouwer, C. D. A., et al. (2019). Impact of early events and lifestyle on the gut microbiota and metabolic phenotypes in young school-age children. Microbiome 7, 2. doi:10.1186/s40168-018-0608-z.

Adak, A., and Khan, M. R. (2019). An insight into gut microbiota and its functionalities. Cell Mol. Life Sci. 76, 473-493. doi:10.1007/s00018-018-2943-4.

Ananthakrishnan, A. N. (2020). Impact of diet on risk of IBD. Crohns Colitis 3602. doi:10.1093/crocol/otz054.

De Angelis, M., Ferrocino, I., Calabrese, F. M., De Filippis, F., Cavallo, N., Siragusa, S., Rampelli, S., Di Cagno, R., Rantsiou, K., Vannini, L., et al. (2020). Diet influences the functions of the human intestinal microbiome. Sci. Rep. 10, 4247. doi:10.1038/s41598-020-61192-y.

Barone, M., Turroni, S., Rampelli, S., Soverini, M., D’Amico, F., Biagi, E., Brigidi, P., Troiani, E., and Candela, M. (2019). Gut microbiome response to a modern Paleolithic diet in a Western lifestyle context. PLoS One 14, e0220619. doi:10.1371/journal.pone.0220619.

Bashiardes, S., Thaiss, C. A., and Elinav, E. (2016). It's in the milk: feeding the microbiome to promote infant growth. Cell Metab. 23, 393-394. doi:10.1016/j.cmet.2016.02.015.

Belkaid, Y., and Hand, T. W. (2014). Role of the microbiota in immunity and inflammation. Cell 157, 121-141. doi:10.1016/j.cell.2014.03.011. 
Berger, B., Porta, N., Foata, F., Grathwohl, D., Delley, M., Moine, D., Charpagne, A., Siegwald, L., Descombes, P., Alliet, P., et al. (2020a). Linking human milk oligosaccharides, infant fecal community types, and later risk to require antibiotics. MBio 11. doi:10.1128/mBio.03196-19.

Berger, P. K., Plows, J. F., Jones, R. B., Alderete, T. L., Yonemitsu, C., Poulsen, M., Ryoo, J. H., Peterson, B. S., Bode, L., and Goran, M. I. (2020b). Human milk oligosaccharide 2'fucosyllactose links feedings at 1 month to cognitive development at 24 months in infants of normal and overweight mothers. PLoS One 15, e0228323. doi:10.1371/journal.pone.0228323.

Brooks, A. W., Priya, S., Blekhman, R., and Bordenstein, S. R. (2018). Gut microbiota diversity across ethnicities in the United States. PLoS Biol. 16, e2006842. doi:10.1371/journal.pbio.2006842.

Buford, T. W. (2017). (Dis)Trust your gut: the gut microbiome in age-related inflammation, health, and disease. Microbiome 5, 80. doi:10.1186/s40168-017-0296-0.

Cardona, F., Andrés-Lacueva, C., Tulipani, S., Tinahones, F. J., and Queipo-Ortuño, M. I. (2013). Benefits of polyphenols on gut microbiota and implications in human health. J. Nutr. Biochem. 24, 1415-1422. doi:10.1016/j.jnutbio.2013.05.001.

Carmody, R. N., Bisanz, J. E., Bowen, B. P., Maurice, C. F., Lyalina, S., Louie, K. B., Treen, D., Chadaideh, K. S., Maini Rekdal, V., Bess, E. N., et al. (2019). Cooking shapes the structure and function of the gut microbiome. Nat. Microbiol. 4, 2052-2063. doi:10.1038/s41564019-0569-4.

Chassaing, B., Van deaaa 1Wiele, T., De Bodt, J., Marzorati, M., and Gewirtz, A. T. (2017). Dietary emulsifiers directly alter human microbiota composition and gene expression ex vivo potentiating intestinal inflammation. Gut 66, 1414-1427. doi:10.1136/gutjnl-2016313099.

Chassaing, B., Koren, O., Goodrich, J. K., Poole, A. C., Srinivasan, S., Ley, R. E., and Gewirtz, A. T. (2015). Dietary emulsifiers impact the mouse gut microbiota promoting colitis and metabolic syndrome. Nature 519, 92-96. doi:10.1038/nature14232.

Chen, K., Xie, K., Liu, Z., Nakasone, Y., Sakao, K., Hossain, A., and Hou, D.-X. (2019a). Preventive effects and mechanisms of garlic on dyslipidemia and gut microbiome dysbiosis. Nutrients 11. doi:10.3390/nu11061225.

Chen, X., Zhou, Y., and Yu, J. (2019b). Exosome-like Nanoparticles from Ginger Rhizomes Inhibited NLRP3 Inflammasome Activation. Mol. Pharm. 16, 2690-2699. doi:10.1021/acs.molpharmaceut.9b00246.

Chu, D. M., Ma, J., Prince, A. L., Antony, K. M., Seferovic, M. D., and Aagaard, K. M. (2017). Maturation of the infant microbiome community structure and function across multiple body sites and in relation to mode of delivery. Nat. Med. 23, 314-326. doi: $10.1038 / \mathrm{nm} .4272$.

Clemente, J. C., Pehrsson, E. C., Blaser, M. J., Sandhu, K., Gao, Z., Wang, B., Magris, M., Hidalgo, G., Contreras, M., Noya-Alarcón, Ó., et al. (2015). The microbiome of uncontacted Amerindians. Sci. Adv. 1. doi:10.1126/sciadv.1500183.

Cordain, L., Eaton, S. B., Sebastian, A., Mann, N., Lindeberg, S., Watkins, B. A., O’Keefe, J. H., and Brand-Miller, J. (2005). Origins and evolution of the Western diet: health implications for the 21st century. Am. J. Clin. Nutr. 81, 341-354. doi:10.1093/ajcn.81.2.341.

David, L. A., Maurice, C. F., Carmody, R. N., Gootenberg, D. B., Button, J. E., Wolfe, B. E., Ling, A. V., Devlin, A. S., Varma, Y., Fischbach, M. A., et al. (2014). Diet rapidly and 
reproducibly alters the human gut microbiome. Nature 505, 559-563. doi:10.1038/nature12820.

de Castro, M. M., Corona, L. P., Pascoal, L. B., Miyamoto, J. É., Ignacio-Souza, L. M., de Lourdes Setsuko Ayrizono, M., Torsoni, M. A., Torsoni, A. S., Leal, R. F., and Milanski, M. (2020). Dietary patterns associated to clinical aspects in crohn's disease patients. Sci. Rep. 10, 7033. doi:10.1038/s41598-020-64024-1.

Dehingia, M., Thangjam Devi, K., Talukdar, N. C., Talukdar, R., Reddy, N., Mande, S. S., Deka, M., and Khan, M. R. (2015). Gut bacterial diversity of the tribes of India and comparison with the worldwide data. Sci. Rep. 5, 18563. doi:10.1038/srep18563.

Derrien, M., Alvarez, A.-S., and de Vos, W. M. (2019). The gut microbiota in the first decade of life. Trends Microbiol. 27, 997-1010. doi:10.1016/j.tim.2019.08.001.

Dethlefsen, L., Huse, S., Sogin, M. L., and Relman, D. A. (2008). The pervasive effects of an antibiotic on the human gut microbiota, as revealed by deep $16 \mathrm{~S}$ rRNA sequencing. PLoS Biol. 6, e280. doi:10.1371/journal.pbio.0060280.

Drake, I., Sonestedt, E., Ericson, U., Wallström, P., and Orho-Melander, M. (2018). A Western dietary pattern is prospectively associated with cardio-metabolic traits and incidence of the metabolic syndrome. Br. J. Nutr. 119, 1168-1176. doi:10.1017/S000711451800079X.

Falony, G., Joossens, M., Vieira-Silva, S., Wang, J., Darzi, Y., Faust, K., Kurilshikov, A., Bonder, M. J., Valles-Colomer, M., Vandeputte, D., et al. (2016). Population-level analysis of gut microbiome variation. Science 352, 560-564. doi:10.1126/science.aad3503.

Ferreira-Halder, C. V., Faria, A. V. de S., and Andrade, S. S. (2017). Action and function of Faecalibacterium prausnitzii in health and disease. Best Pract Res Clin Gastroenterol 31, 643-648. doi:10.1016/j.bpg.2017.09.011.

De Filippis, F., Pellegrini, N., Vannini, L., Jeffery, I. B., La Storia, A., Laghi, L., Serrazanetti, D. I., Di Cagno, R., Ferrocino, I., Lazzi, C., et al. (2016). High-level adherence to a Mediterranean diet beneficially impacts the gut microbiota and associated metabolome. Gut 65, 1812-1821. doi:10.1136/gutjnl-2015-309957.

De Filippo, C., Cavalieri, D., Di Paola, M., Ramazzotti, M., Poullet, J. B., Massart, S., Collini, S., Pieraccini, G., and Lionetti, P. (2010). Impact of diet in shaping gut microbiota revealed by a comparative study in children from Europe and rural Africa. Proc. Natl. Acad. Sci. USA 107, 14691-14696. doi:10.1073/pnas.1005963107.

Garcia-Mantrana, I., Selma-Royo, M., Alcantara, C., and Collado, M. C. (2018). Shifts on gut microbiota associated to mediterranean diet adherence and specific dietary intakes on general adult population. Front. Microbiol. 9, 890. doi:10.3389/fmicb.2018.00890.

Gevers, D., Kugathasan, S., Denson, L. A., Vázquez-Baeza, Y., Van Treuren, W., Ren, B., Schwager, E., Knights, D., Song, S. J., Yassour, M., et al. (2014). The treatment-naive microbiome in new-onset Crohn's disease. Cell Host Microbe 15, 382-392. doi:10.1016/j.chom.2014.02.005.

Girard, C., Tromas, N., Amyot, M., and Shapiro, B. J. (2017). Gut microbiome of the canadian arctic inuit. mSphere 2. doi:10.1128/mSphere.00297-16.

Gomez, A., Petrzelkova, K. J., Burns, M. B., Yeoman, C. J., Amato, K. R., Vlckova, K., Modry, D., Todd, A., Jost Robinson, C. A., Remis, M. J., et al. (2016). Gut microbiome of coexisting baka pygmies and bantu reflects gradients of traditional subsistence patterns. Cell Rep. 14, 2142-2153. doi:10.1016/j.celrep.2016.02.013.

Green, N., Miller, T., Suskind, D., and Lee, D. (2019). A review of dietary therapy for IBD and a vision for the future. Nutrients 11. doi:10.3390/nu11050947. 
Green, R., Milner, J., Joy, E. J. M., Agrawal, S., and Dangour, A. D. (2016). Dietary patterns in India: a systematic review. Br. J. Nutr. 116, 142-148. doi:10.1017/S0007114516001598.

Grundy, M. M.-L., Edwards, C. H., Mackie, A. R., Gidley, M. J., Butterworth, P. J., and Ellis, P. R. (2016). Re-evaluation of the mechanisms of dietary fibre and implications for macronutrient bioaccessibility, digestion and postprandial metabolism. Br. J. Nutr. 116, 816-833. doi:10.1017/S0007114516002610.

Gupta, V. K., Paul, S., and Dutta, C. (2017). Geography, Ethnicity or Subsistence-Specific Variations in Human Microbiome Composition and Diversity. Front. Microbiol. 8, 1162. doi:10.3389/fmicb.2017.01162.

Heiman, M. L., and Greenway, F. L. (2016). A healthy gastrointestinal microbiome is dependent on dietary diversity. Mol. Metab. 5, 317-320. doi:10.1016/j.molmet.2016.02.005.

Ho, N. T., Li, F., Lee-Sarwar, K. A., Tun, H. M., Brown, B. P., Pannaraj, P. S., Bender, J. M., Azad, M. B., Thompson, A. L., Weiss, S. T., et al. (2018). Meta-analysis of effects of exclusive breastfeeding on infant gut microbiota across populations. Nat. Commun. 9, 4169. doi:10.1038/s41467-018-06473-x.

Jandhyala, S. M., Talukdar, R., Subramanyam, C., Vuyyuru, H., Sasikala, M., and Nageshwar Reddy, D. (2015). Role of the normal gut microbiota. World J. Gastroenterol. 21, 87878803. doi:10.3748/wjg.v21.i29.8787.

Jha, A. R., Davenport, E. R., Gautam, Y., Bhandari, D., Tandukar, S., Ng, K. M., Fragiadakis, G. K., Holmes, S., Gautam, G. P., Leach, J., et al. (2018). Gut microbiome transition across a lifestyle gradient in Himalaya. PLoS Biol. 16, e2005396. doi:10.1371/journal.pbio.2005396.

Jin, C., Xia, J., Wu, S., Tu, W., Pan, Z., Fu, Z., Wang, Y., and Jin, Y. (2018). Insights into a possible influence on gut microbiota and intestinal barrier function during chronic exposure of mice to imazalil. Toxicol. Sci. 162, 113-123. doi:10.1093/toxsci/kfx227.

Jin, Y., Lu, L., Tu, W., Luo, T., and Fu, Z. (2019). Impacts of polystyrene microplastic on the gut barrier, microbiota and metabolism of mice. Sci. Total Environ. 649, 308-317. doi:10.1016/j.scitotenv.2018.08.353.

Joly Condette, C., Bach, V., Mayeur, C., Gay-Quéheillard, J., and Khorsi-Cauet, H. (2015). Chlorpyrifos exposure during perinatal period affects intestinal microbiota associated with delay of maturation of digestive tract in rats. J. Pediatr. Gastroenterol. Nutr. 61, 30-40. doi:10.1097/MPG.0000000000000734.

Karasov, W. H., and Douglas, A. E. (2013). Comparative digestive physiology. Compr. Physiol. 3, 741-783. doi:10.1002/cphy.c110054.

Kim, H., Sitarik, A. R., Woodcroft, K., Johnson, C. C., and Zoratti, E. (2019). Birth mode, breastfeeding, pet exposure, and antibiotic use: associations with the gut microbiome and sensitization in children. Curr. Allergy Asthma Rep. 19, 22. doi:10.1007/s11882-019-08519.

Kim, K.-S., Lee, Y.-M., Kim, S. G., Lee, I.-K., Lee, H.-J., Kim, J.-H., Kim, J., Moon, H.-B., Jacobs, D. R., and Lee, D.-H. (2014). Associations of organochlorine pesticides and polychlorinated biphenyls in visceral vs. subcutaneous adipose tissue with type 2 diabetes and insulin resistance. Chemosphere 94, 151-157. doi:10.1016/j.chemosphere.2013.09.066.

Kim, S., and Jazwinski, S. M. (2018). The Gut Microbiota and Healthy Aging: A Mini-Review. Gerontology 64, 513-520. doi:10.1159/000490615. 
Kostic, A. D., Xavier, R. J., and Gevers, D. (2014). The microbiome in inflammatory bowel disease: current status and the future ahead. Gastroenterology 146, 1489-1499. doi:10.1053/j.gastro.2014.02.009.

Lazar, V., Ditu, L.-M., Pircalabioru, G. G., Gheorghe, I., Curutiu, C., Holban, A. M., Picu, A., Petcu, L., and Chifiriuc, M. C. (2018). Aspects of gut microbiota and immune system interactions in infectious diseases, immunopathology, and cancer. Front. Immunol. 9, 1830. doi:10.3389/fimmu.2018.01830.

Lewis, J. D. (2016). The role of diet in inflammatory bowel disease. Gastroenterol. Hepatol. (N.Y.) $12,51-53$.

Liu, W., Zhang, J., Wu, C., Cai, S., Huang, W., Chen, J., Xi, X., Liang, Z., Hou, Q., Zhou, B., et al. (2016). Unique Features of Ethnic Mongolian Gut Microbiome revealed by metagenomic analysis. Sci. Rep. 6, 34826. doi:10.1038/srep34826.

Lloyd-Price, J., Arze, C., Ananthakrishnan, A. N., Schirmer, M., Avila-Pacheco, J., Poon, T. W., Andrews, E., Ajami, N. J., Bonham, K. S., Brislawn, C. J., et al. (2019). Multi-omics of the gut microbial ecosystem in inflammatory bowel diseases. Nature 569, 655-662. doi:10.1038/s41586-019-1237-9.

Lopez-Siles, M., Martinez-Medina, M., Surís-Valls, R., Aldeguer, X., Sabat-Mir, M., Duncan, S. H., Flint, H. J., and Garcia-Gil, L. J. (2016). Changes in the Abundance of Faecalibacterium prausnitzii Phylogroups I and II in the Intestinal Mucosa of Inflammatory Bowel Disease and Patients with Colorectal Cancer. Inflamm. Bowel Dis. 22, 28-41. doi:10.1097/MIB.0000000000000590.

Machiels, K., Joossens, M., Sabino, J., De Preter, V., Arijs, I., Eeckhaut, V., Ballet, V., Claes, K., Van Immerseel, F., Verbeke, K., et al. (2014). A decrease of the butyrate-producing species Roseburia hominis and Faecalibacterium prausnitzii defines dysbiosis in patients with ulcerative colitis. Gut 63, 1275-1283. doi:10.1136/gutjnl-2013-304833.

Maier, L., Pruteanu, M., Kuhn, M., Zeller, G., Telzerow, A., Anderson, E. E., Brochado, A. R., Fernandez, K. C., Dose, H., Mori, H., et al. (2018). Extensive impact of non-antibiotic drugs on human gut bacteria. Nature 555, 623-628. doi:10.1038/nature25979.

Martinez-Medina, M., Denizot, J., Dreux, N., Robin, F., Billard, E., Bonnet, R., DarfeuilleMichaud, A., and Barnich, N. (2014). Western diet induces dysbiosis with increased E coli in CEABAC10 mice, alters host barrier function favouring AIEC colonisation. Gut 63, 116-124. doi:10.1136/gutjnl-2012-304119.

Matijašić, B. B., Obermajer, T., Lipoglavšek, L., Grabnar, I., Avguštin, G., and Rogelj, I. (2014). Association of dietary type with fecal microbiota in vegetarians and omnivores in Slovenia. Eur J Nutr 53, 1051-1064. doi:10.1007/s00394-013-0607-6.

McDonald, D., Hyde, E., Debelius, J. W., Morton, J. T., Gonzalez, A., Ackermann, G., Aksenov, A. A., Behsaz, B., Brennan, C., Chen, Y., et al. (2018). American gut: an open platform for citizen science microbiome research. mSystems 3. doi:10.1128/mSystems.00031-18.

Di Meo, F., Margarucci, S., Galderisi, U., Crispi, S., and Peluso, G. (2019). Curcumin, gut microbiota, and neuroprotection. Nutrients 11. doi:10.3390/nu11102426.

Nicholson, J. K., Holmes, E., Kinross, J., Burcelin, R., Gibson, G., Jia, W., and Pettersson, S. (2012). Host-gut microbiota metabolic interactions. Science 336, 1262-1267. doi:10.1126/science.1223813.

O’Toole, P. W., and Jeffery, I. B. (2015). Gut microbiota and aging. Science 350, 1214-1215. doi:10.1126/science.aac8469. 
Obregon-Tito, A. J., Tito, R. Y., Metcalf, J., Sankaranarayanan, K., Clemente, J. C., Ursell, L. K., Zech Xu, Z., Van Treuren, W., Knight, R., Gaffney, P. M., et al. (2015). Subsistence strategies in traditional societies distinguish gut microbiomes. Nat. Commun. 6, 6505. doi:10.1038/ncomms7505.

Oldenburg, C. E., Sié, A., Coulibaly, B., Ouermi, L., Dah, C., Tapsoba, C., Bärnighausen, T., Ray, K. J., Zhong, L., Cummings, S., et al. (2018). Effect of commonly used pediatric antibiotics on gut microbial diversity in preschool children in burkina faso: A randomized clinical trial. Open Forum Infect. Dis. 5, ofy289. doi:10.1093/ofid/ofy289.

Partridge, D., Lloyd, K. A., Rhodes, J. M., Walker, A. W., Johnstone, A. M., and Campbell, B. J. (2019). Food additives: Assessing the impact of exposure to permitted emulsifiers on bowel and metabolic health - introducing the FADiets study. Nutr. Bull. 44, 329-349. doi:10.1111/nbu.12408.

Pigneur, B., and Ruemmele, F. M. (2019). Nutritional interventions for the treatment of IBD: current evidence and controversies. Therap. Adv. Gastroenterol. 12, 1756284819890534. doi:10.1177/1756284819890534.

Quagliariello, A., Di Paola, M., De Fanti, S., Gnecchi-Ruscone, G. A., Martinez-Priego, L., PérezVillaroya, D., Sherpa, M. G., Sherpa, P. T., Marinelli, G., Natali, L., et al. (2019). Gut microbiota composition in Himalayan and Andean populations and its relationship with diet, lifestyle and adaptation to the high-altitude environment. J. Anthropol. Sci. 96, 189208. doi:10.4436/JASS.97007.

Rampelli, S., Candela, M., Turroni, S., Biagi, E., Collino, S., Franceschi, C., O’Toole, P. W., and Brigidi, P. (2013). Functional metagenomic profiling of intestinal microbiome in extreme ageing. Aging (Albany, NY) 5, 902-912. doi:10.18632/aging.100623.

Réquilé, M., Gonzàlez Alvarez, D. O., Delanaud, S., Rhazi, L., Bach, V., Depeint, F., and KhorsiCauet, H. (2018). Use of a combination of in vitro models to investigate the impact of chlorpyrifos and inulin on the intestinal microbiota and the permeability of the intestinal mucosa. Environ. Sci. Pollut. Res. Int. 25, 22529-22540. doi:10.1007/s11356-018-2332-4.

Reygner, J., Lichtenberger, L., Elmhiri, G., Dou, S., Bahi-Jaber, N., Rhazi, L., Depeint, F., Bach, V., Khorsi-Cauet, H., and Abdennebi-Najar, L. (2016). Inulin Supplementation Lowered the Metabolic Defects of Prolonged Exposure to Chlorpyrifos from Gestation to Young Adult Stage in Offspring Rats. PLoS One 11, e0164614. doi:10.1371/journal.pone.0164614.

Roberts, C. L., Keita, A. V., Duncan, S. H., O’Kennedy, N., Söderholm, J. D., Rhodes, J. M., and Campbell, B. J. (2010). Translocation of Crohn's disease Escherichia coli across M-cells: contrasting effects of soluble plant fibres and emulsifiers. Gut 59, 1331-1339. doi:10.1136/gut.2009.195370.

Romagnolo, D. F., and Selmin, O. I. (2017). Mediterranean diet and prevention of chronic diseases. Nutr. Today 52, 208-222. doi:10.1097/NT.0000000000000228.

Salli, K., Anglenius, H., Hirvonen, J., Hibberd, A. A., Ahonen, I., Saarinen, M. T., Tiihonen, K., Maukonen, J., and Ouwehand, A. C. (2019). The effect of 2'-fucosyllactose on simulated infant gut microbiome and metabolites; a pilot study in comparison to GOS and lactose. Sci. Rep. 9, 13232. doi:10.1038/s41598-019-49497-z.

Sarmiento, M. R. A., de Paula, T. O., Borges, F. M., Ferreira-Machado, A. B., Resende, J. A., Moreira, A. P. B., Dutra Luquetti, S. C. P., Cesar, D. E., da Silva, V. L., and Diniz, C. G. (2019). Obesity, Xenobiotic Intake and Antimicrobial-Resistance Genes in the Human 
Gastrointestinal Tract: A Comparative Study of Eutrophic, Overweight and Obese Individuals. Genes (Basel) 10. doi:10.3390/genes10050349.

Schirmer, M., Franzosa, E. A., Lloyd-Price, J., McIver, L. J., Schwager, R., Poon, T. W., Ananthakrishnan, A. N., Andrews, E., Barron, G., Lake, K., et al. (2018). Dynamics of metatranscription in the inflammatory bowel disease gut microbiome. Nat. Microbiol. 3, 337-346. doi:10.1038/s41564-017-0089-z.

Schnorr, S. L., Candela, M., Rampelli, S., Centanni, M., Consolandi, C., Basaglia, G., Turroni, S., Biagi, E., Peano, C., Severgnini, M., et al. (2014). Gut microbiome of the Hadza huntergatherers. Nat. Commun. 5, 3654. doi:10.1038/ncomms4654.

Shondelmyer, K., Knight, R., Sanivarapu, A., Ogino, S., and Vanamala, J. K. P. (2018). Ancient thali diet: gut microbiota, immunity, and health. Yale J Biol Med 91, 177-184.

Shreiner, A. B., Kao, J. Y., and Young, V. B. (2015). The gut microbiome in health and in disease. Curr. Opin. Gastroenterol. 31, 69-75. doi:10.1097/MOG.0000000000000139.

Singh, R. K., Chang, H.-W., Yan, D., Lee, K. M., Ucmak, D., Wong, K., Abrouk, M., Farahnik, B., Nakamura, M., Zhu, T. H., et al. (2017). Influence of diet on the gut microbiome and implications for human health. J. Transl. Med. 15, 73. doi:10.1186/s12967-017-1175-y.

Smits, S. A., Leach, J., Sonnenburg, E. D., Gonzalez, C. G., Lichtman, J. S., Reid, G., Knight, R., Manjurano, A., Changalucha, J., Elias, J. E., et al. (2017). Seasonal cycling in the gut microbiome of the Hadza hunter-gatherers of Tanzania. Science 357, 802-806. doi:10.1126/science.aan4834.

Sonnenburg, E. D., Smits, S. A., Tikhonov, M., Higginbottom, S. K., Wingreen, N. S., and Sonnenburg, J. L. (2016). Diet-induced extinctions in the gut microbiota compound over generations. Nature 529, 212-215. doi:10.1038/nature16504.

Spreadbury, I. (2012). Comparison with ancestral diets suggests dense acellular carbohydrates promote an inflammatory microbiota, and may be the primary dietary cause of leptin resistance and obesity. Diabetes. Metab. Syndr. Obes. 5, 175-189. doi:10.2147/DMSO.S33473.

Stagaman, K., Cepon-Robins, T. J., Liebert, M. A., Gildner, T. E., Urlacher, S. S., Madimenos, F. C., Guillemin, K., Snodgrass, J. J., Sugiyama, L. S., and Bohannan, B. J. M. (2018). Market Integration Predicts Human Gut Microbiome Attributes across a Gradient of Economic Development. mSystems 3. doi:10.1128/mSystems.00122-17.

Stefler, D., Brett, D., Sarkadi-Nagy, E., Kopczynska, E., Detchev, S., Bati, A., Scrob, M., Koenker, D., Aleksov, B., Douarin, E., et al. (2020). Traditional Eastern European diet and mortality: prospective evidence from the HAPIEE study. Eur J Nutr. doi:10.1007/s00394-020-023199.

Stewart, C. J., Ajami, N. J., O’Brien, J. L., Hutchinson, D. S., Smith, D. P., Wong, M. C., Ross, M. C., Lloyd, R. E., Doddapaneni, H., Metcalf, G. A., et al. (2018). Temporal development of the gut microbiome in early childhood from the TEDDY study. Nature 562, 583-588. doi:10.1038/s41586-018-0617-x.

Suez, J., Korem, T., Zeevi, D., Zilberman-Schapira, G., Thaiss, C. A., Maza, O., Israeli, D., Zmora, N., Gilad, S., Weinberger, A., et al. (2014). Artificial sweeteners induce glucose intolerance by altering the gut microbiota. Nature 514, 181-186. doi:10.1038/nature13793.

Svolos, V., Hansen, R., Nichols, B., Quince, C., Ijaz, U. Z., Papadopoulou, R. T., Edwards, C. A., Watson, D., Alghamdi, A., Brejnrod, A., et al. (2019). Treatment of Active Crohn's Disease With an Ordinary Food-based Diet That Replicates Exclusive Enteral Nutrition. Gastroenterology 156, 1354-1367.e6. doi:10.1053/j.gastro.2018.12.002. 
Turnbaugh, P. J., Ridaura, V. K., Faith, J. J., Rey, F. E., Knight, R., and Gordon, J. I. (2009). The effect of diet on the human gut microbiome: a metagenomic analysis in humanized gnotobiotic mice. Sci. Transl. Med. 1, 6ra14. doi:10.1126/scitranslmed.3000322.

Valles-Colomer, M., Falony, G., Darzi, Y., Tigchelaar, E. F., Wang, J., Tito, R. Y., Schiweck, C., Kurilshikov, A., Joossens, M., Wijmenga, C., et al. (2019). The neuroactive potential of the human gut microbiota in quality of life and depression. Nat. Microbiol. 4, 623-632. doi:10.1038/s41564-018-0337-x.

van den Elsen, L. W. J., Garssen, J., Burcelin, R., and Verhasselt, V. (2019). Shaping the gut microbiota by breastfeeding: the gateway to allergy prevention? Front. Pediatr. 7, 47. doi:10.3389/fped.2019.00047.

Vanegas, S. M., Meydani, M., Barnett, J. B., Goldin, B., Kane, A., Rasmussen, H., Brown, C., Vangay, P., Knights, D., Jonnalagadda, S., et al. (2017). Substituting whole grains for refined grains in a 6-wk randomized trial has a modest effect on gut microbiota and immune and inflammatory markers of healthy adults. Am. J. Clin. Nutr. 105, 635-650. doi:10.3945/ajen.116.146928.

Vatanen, T., Franzosa, E. A., Schwager, R., Tripathi, S., Arthur, T. D., Vehik, K., Lernmark, Å., Hagopian, W. A., Rewers, M. J., She, J.-X., et al. (2018). The human gut microbiome in early-onset type 1 diabetes from the TEDDY study. Nature 562, 589-594. doi:10.1038/s41586-018-0620-2.

Viennois, E., Merlin, D., Gewirtz, A. T., and Chassaing, B. (2017). Dietary Emulsifier-Induced Low-Grade Inflammation Promotes Colon Carcinogenesis. Cancer Res. 77, 27-40. doi:10.1158/0008-5472.CAN-16-1359.

Wang, M., Li, M., Wu, S., Lebrilla, C. B., Chapkin, R. S., Ivanov, I., and Donovan, S. M. (2015). Fecal microbiota composition of breast-fed infants is correlated with human milk oligosaccharides consumed. J. Pediatr. Gastroenterol. Nutr. 60, 825-833. doi:10.1097/MPG.0000000000000752.

Willing, B. P., Russell, S. L., and Finlay, B. B. (2011). Shifting the balance: antibiotic effects on host-microbiota mutualism. Nat. Rev. Microbiol. 9, 233-243. doi:10.1038/nrmicro2536.

Wu, G. D., Chen, J., Hoffmann, C., Bittinger, K., Chen, Y.-Y., Keilbaugh, S. A., Bewtra, M., Knights, D., Walters, W. A., Knight, R., et al. (2011). Linking long-term dietary patterns with gut microbial enterotypes. Science 334, 105-108. doi:10.1126/science.1208344.

$\mathrm{Wu}, \mathrm{H} .-\mathrm{J}$. , and $\mathrm{Wu}, \mathrm{E}$. (2012). The role of gut microbiota in immune homeostasis and autoimmunity. Gut Microbes 3, 4-14. doi:10.4161/gmic.19320.

Yasir, M., Angelakis, E., Bibi, F., Azhar, E. I., Bachar, D., Lagier, J. C., Gaborit, B., Hassan, A. M., Jiman-Fatani, A. A., Alshali, K. Z., et al. (2015). Comparison of the gut microbiota of people in France and Saudi Arabia. Nutr. Diabetes 5, e153. doi:10.1038/nutd.2015.3.

Yatsunenko, T., Rey, F. E., Manary, M. J., Trehan, I., Dominguez-Bello, M. G., Contreras, M., Magris, M., Hidalgo, G., Baldassano, R. N., Anokhin, A. P., et al. (2012). Human gut microbiome viewed across age and geography. Nature 486, 222-227. doi:10.1038/nature11053.

Yuan, X., Pan, Z., Jin, C., Ni, Y., Fu, Z., and Jin, Y. (2019). Gut microbiota: An underestimated and unintended recipient for pesticide-induced toxicity. Chemosphere 227, 425-434. doi:10.1016/j.chemosphere.2019.04.088.

Zhang, X., Liu, S., Wang, Y., Hu, H., Li, L., Wu, Y., Cao, D., Cai, Y., Zhang, J., and Zhang, X. (2019). Interleukin-22 regulates the homeostasis of the intestinal epithelium during inflammation. Int. J. Mol. Med. 43, 1657-1668. doi:10.3892/ijmm.2019.4092. 
Zhernakova, A., Kurilshikov, A., Bonder, M. J., Tigchelaar, E. F., Schirmer, M., Vatanen, T., Mujagic, Z., Vila, A. V., Falony, G., Vieira-Silva, S., et al. (2016). Population-based metagenomics analysis reveals markers for gut microbiome composition and diversity. Science 352, 565-569. doi:10.1126/science.aad3369.

Zhong, H., Penders, J., Shi, Z., Ren, H., Cai, K., Fang, C., Ding, Q., Thijs, C., Blaak, E. E., Stehouwer, C. D. A., et al. (2019). Impact of early events and lifestyle on the gut microbiota and metabolic phenotypes in young school-age children. Microbiome 7, 2. doi:10.1186/s40168-018-0608-z.

Zinöcker, M. K., and Lindseth, I. A. (2018). The Western Diet-Microbiome-Host Interaction and Its Role in Metabolic Disease. Nutrients 10. doi:10.3390/nu10030365. 